\title{
Study on Current Situation and Countermeasures of the Martial Arts Inheritance of Qiang Group
}

\author{
Wencan Fu \\ Department of physical education, Aba Teachers University, Wenchuan, Sichuan, 623004, China
}

Keywords: Qiang Martial Art, Folklore, loricae dance, War Dance, Inheritance, Preservation Countermeasure

\begin{abstract}
As a alienation branch under Chinese national assimilation and national fusion, Qiang has its unique ethnic culture and history of development It is the integration of multiple ethnic Han, Yi, Tibetan and other ethnic cultures, after generation to generation of heritage for many years, forms the new nation, so Qiang is a collection of a variety of cultural heritages of the special nation. This paper introduces an important branch-- the origin and history of folk inheritance of Qiang martial arts. At the same time, it analyzes an important war dance Qiang with the nature of martial arts -- the investigation and preservation countermeasure of "loricae dance".
\end{abstract}

\section{Introduction}

In the primitive society, in order to compete for resources and territory, plunder and revenge were basically the main theme in human life. In the frequent wars, the Ethnic groups created the habits of learning martial arts and war game simulation, formed the Wushu culture with offensive and defensive nature. The Qiang people created the martial arts of Qiang group in such a living environment, and it helped people to fight and rob resources, even applied to hunting and gathering production work.

\section{The analysis of the origin of Qiang Wushu}

Martial arts of Qiang group is a conscious and regular fighting behavior formed in the productive labor of the ancient Qiang community, which originated in the struggle between people and animals when hunting. Long in the past, the Qiang people summarized the experience from the combat action, formed a special mode of practice, and it has also become the beginning of martial arts of Qiang group. From the perspective of the ancient Qiang people's private ideas and the protection of the internal property, this is a contradiction between human and animal, man and man, community and community. It can not only carry out personal defense, but also attack other people. Especially in Qiang and other ethnic war, martial arts of Qiang nationality individual combat skills and group combat tactics has also been rapid formation of opportunities, so in the long process of development, the connotation of martial arts of Qiang group is gradually enriched and specific. According to research, martial arts of Qiang reason for developing rapidly and they live in a compact community of the Qinghai Tibet plateau area about, here long-term social environment is harsh and tough natural environment, makes the Qiang people have to rely on the use of force to fight for more resources and land, cultivate the their violent and advocating the force of character. Local shaman described the ancient Qiang people in the hunting and war in the formation of the basic characteristics of the nation." This also showed the attitude in the history of the evolution of Qiang.

Process of continuous aggression and plunder of Qiang, Qiang martial arts are also increasingly developed, such as "Qiang" is Qiang swim herdsmen, invented a special boxing. Early in the Qin and Han Dynasties, generations living in the Qinghai Tibet Plateau Qiang in the daily hunt and fight outside, forming a its nomadic this unique boxing. In 112 BC, Hun combined on the Qinghai Tibet Plateau of the Qiang ethnic group launched wars of aggression, defeated the Qiang nationality, so that they can continue to retreat to Qinghai Lake to the west area. While in the park during the period of 136 165, has been ranked in the Qinghai Lake area of Qiang and Han Dynasty to the war. Also in the two section of Qiang war, their "Qiang" has been rapid development. To the Jin Dynasty, "Qiang" can 
continue to pass, it is this sense of martial arts carry forward, just let the ancient Qiang people from the derivative invented the archery, horse riding, climbing, jumping, martial arts, including with the length of the weapon fighting techniques. Tang to the Five Dynasties later, the Tubo Dynasty once thriving fading the Qiang and to promote the development of Tibetan, so "Qiang" is absorbed by the Tibetans, combined with their own national straightforward fierce boxing Road, development leads to a Tibetan characteristics of "Ba Quan" martial arts, "Qiang" is to some degree by Tibetans and carry forward the tradition, from "Qiang" this statement also gradually disappeared from the scene.

On the other hand, Qiang community life in Northwest Sichuan Minjiang River in the upper reaches of the Taoism is also the birthplace of, so in a certain extent the structure and morphology of the martial arts of Qiang nationality, guiding ideology inevitably from Taoist Wushu effect. In the years of Qiang martial arts and cultural development, the martial arts of Qiang nationality was nurtured by thoughts of Taoism in the practice of the exercises, health care, and gradually formed a Qiang Qigong, so Qiang is also our country national minority in the early development of Qigong in the nation. Qiang Qigong the earliest by a Qiang Duan Gong (performed in the ancient witchcraft male Qiang wizard, also known as Shibi) master and due to the belief of Shibi and Taoism in a certain extent are highly conserved nature, so Qiang Qigong Wu in dress, qigong footwork and acrobatics read Scripture spells are and Taoist Wushu in exactly the same can said Qiang of Wushu and Qigong is a Taoist Wushu in a form of alienation of inheritance is not too much. Until now, the Qiang Qigong has been preserved and developed ${ }^{[1]}$.

\section{About the folklore and culture mar of Qiang Wushu}

In the Qiang Folk Culture, Qiang people brave victory character is well known. Wenchuan County, the turnip village, there is such an ancient folk legend, it is such that: "the first big dipper, such as the Big Dipper, ears, such as fan, two eyes, such as ring, tooth thick as a finger, arm length eight feet, two feet tall. Infant milk, and other milk fight, one year old sitting in the breast of the father, brothers don't stop fighting; two-year-old holding sticks and stamp in the chili; three years old in the house call fight jump; splashing fight at the age of four, five years old and penates war; six years and children peer fight; seven placed in wooden ladder office meaning jumping; eight auxiliary parents plow farming; nine year old riding sheep can archery; ten years old can bow to shoot eagles; 11 years old and adult horse racing; twelve toast keep village security risk. "

Qiang is relatively long history of the nation's development of ethnic minorities in China, in this long history and long-term relative occlusive ethnic living environment also allows them to our country minority culture left pretty unsophisticated thick of the ancient Qiang legacy for. So even in the modern Qiang people in the martial arts style, can also vaguely capture the ancient Qiang martial arts culture. Qiang is an aggressive nation, so Qiang martial arts but also throughout the entire ethnic people's life always. Now in the Qiang village, people can not only see those Wudao get sword, fuck arch carrying vector Qiang men, can also see some with martial arts attribute and performance properties of Qiang war dance, such as "Hari" and "loricae dance". The "loricae dance" is the ancient Qiang people in the war with the usual martial arts training as PEP uses the evolution of a battle dance. It is also known as "jump armor", "big funeral dance", is very martial arts characteristics of ancient ritual customs dance. It can also be in the war after the funeral of the sacrifice of soldiers in the war of the dead, also can be in front of the war for the soldiers to fight. In the "loricae dance", the number of participants at least a few people, up to thousands of people, they are wearing leather armor, pheasant head collar straw helmets, armed with spears to form a multi queue, from enclosure and dance to the array dance. They also on the day lifted up his spear and rang the bell, and toward the sky roar in order to encourage forces and the atmosphere not only solemn magnificent, also reveals the Qiang forces, the mighty spirit. Yuan Hong of the "Han" written on the records of the ancient Qiang nationality dance origin: "the armor for the soldiers, longer than the valley, short to ground. Men's soldiers died famous, and thought that the end of the disease, the disease is not bad, and that is not known." And Lu Lun "under a border-fortress" is from the side to show the armor of the Qiang and all the officers and soldiers dance of heroic temperament: "wild screen open a sumptuous banquet, Qiang Rong Helao rotation. Drunk and golden armour dance, thunder moving mountains." 


\section{The militarism of Qiang "loricae dance"}

The reason why Qiang martial arts formed the evolution of Qiang "loricae dance", because it reflected the military conquest of the cult of personality and the martial spirit of Qiang people. The Qiang people in imitation of the course of the war will be Qiang martial arts into celebrating the victory of the war of art, formed their own "loricae dance". Therefore, in the hall of elegance Hand Axe spear shield, singing and dancing, worship of the martyrs and the temple was the Qiang people's unique martial arts culture expression form.

In the "loricae dance", "Roxy Guerra" is the name of dancers, many of them were soldiers, dance and clad in armor, holding a sword and a spear, about the contents of the dance and war, weapons, its action is also integrated into the many of the Qiang martial arts, such as mentioned before Qiang and Qigong movements, and so on. In the ancient Qiang language, carat Seeger "has the meaning of funeral ritual, the means of war, which necessarily in the mind of the ancient Qiang ethnic group, in the most glorious death must be for national died, so" loricae dance "also showed the Qiang people combination of dance and martial, martial arts and cultural significance, that is, the Qiang martial arts and dance combined, reflect national win and survive these values of survival. Therefore, the "Dixie Guerra" is the martial arts to celebrate the victory, and to worship the souls of the dance, idolized the martial spirit of the military.

On the other hand, the martial spirit of the Qiang historical origin in their repeated oppression and aggression, starting from $100 \mathrm{BC}$, Qiang people due to years of warfare and displaced, but it is also in this campaign year urgent environment cultivate their love for the character of the force, the development of Wushu and Wushu spirit, so the martial spirit of the Qiang people is reflected in every aspect of the Qiang culture. Qiang society the strong martial breath and Qiang Wushu essence also can not help but into their songs, dances, the passage of time on the formation of Qiang culture in a fault. It also promotes the martial arts of Qiang nationality heritage from generation to generation ${ }^{[2]}$.

\section{The inheritance of Qiang "loricae dance"}

Although "Loricae dance" has a long history, but it was also faced with the situation that was running off. In general, there were three points: first,, now who can jump "loricae dance" most were the man in old age, some of them even have action inconvenience, not dance; second, the "loricae dance" inheritance problems, because the dance is too old, many local people and ancient Qiang culture cognitive interrupted also caused a generation of young learn to have no interest in the "loricae dance"; third, the impact of foreign culture gradually fade Qiang Wushu such traditional national culture.

\section{The tactics to keep and inherit "loricae dance"}

The voluntary of the protection consciousness of the National martial art. First of all, to say, such as "Qiang", "loricae dance" such Qiang martial arts and fighting a dance this have the Qiang tribes in the deep foundation of the masses. Now with the changes of time and the consciousness of the masses, Qiang martial arts seems to come to the end of life, of which the internal cause of the change should is the decisive factor to the Qiang Wushu could not continue to pass. So no matter what the outside call, how to try to protect the Qiang martial arts, if no protective consciousness and enthusiasm for the nation, not from the action up really stay Qiang martial arts, then any practice will be of no avail. Therefore, from the psychological perspective, should be voluntary to protect the quality of social ethics and Qiang Qiang people the most basic martial arts. Qiang martial arts is a traditional cultural characteristics of the ancient Qiang inherent, past, now. So says a national characteristics determine the National People's cognitive, as Harvard literary theorist Edward said as "every nation's each kind of culture develop and protection should follow the existence of a kind of self identity, people want to continue to build and protect the identity, to obtain the identity remain forever. ${ }^{[3]}$ "so contemporary Qiang people should arouse the martial arts of Qiang Nationality from 
the bottom of the inner sense of protection, consciously, voluntary act take the initiative to protect the martial arts of Qiang group.

Legal protection. Like the martial arts of Qiang group, the minority ancient cultural heritage should be subject to legal protection, so since the reform and opening up to the outside world, governments also in support of the minority economy at the same time, for their national culture gave corresponding legal support. In 1998, for example, the National People's Congress on the drafting of the "people's Republic of China National Folk Culture Protection Act," the regulations. And in 2006, which is known as a "living fossil," said the "loricae dance" also in may be incorporated into China's first batch of state-level intangible cultural heritage list. It also reflects the state for the martial arts of Qiang nationality and its value of "loricae dance" for sure. And actually, such as "Qiang", "Qiang qigong" of the ancient Qiang Nationality Traditional Wushu because in the early stages of development by invasion of foreign cultures and a variety of other factors and loss or even lost, "Qiang" is so, recorded only had disappeared from the scene in earthly. So textual research about this aspect, now the relevant scholars and Qiang people also continue to dig and explore, hope can make up for the regret of this ancient ethnic traditional culture involuntary discharge of urine.

The protection of Qiang Wushu under the globalization of national culture. The impact of national cultural globalization for multicultural development is a good thing, but on Qiang the martial tradition, for the scope and direction of strong local characteristics, is a shock. So for the protection of the martial arts of Qiang nationality must do a reasonable position, establish the cognitive status of the Qiang culture subject, in the complex system of cultural globalization find the positioning of their own. National cultural globalization does not mean that the foreign culture will replace the national culture, but should be integrated with the national culture. Such as "loricae dance" this ancient Qiang ethnic dance can also be combined with the modern dance culture, towards diversification, new creative direction, forming more feedback on the thoughts of modern people and the essence of globalization, so that it can find a suitable for their better development of new path in today's society. As New Zealand Maori war dance, in today's sports stadium, people can still see carries national faith athletes team, jump Maori war dance to boost the morale of the team, this is a very good national cultural heritage, let it reflect its proper value in civilization of contemporary society .

\section{Conclusion}

China is a multi-ethnic culture with a body, there are many excellent ancient culture, like the martial arts of Qiang in other ethnic groups, they are waiting the people in the contemporary society to discover and inherit. People should see the martial arts of Qiang group as a culture can not be ignored and separated. Because of the protection and heritage are the continuation of civilization, to make the nationality of Qiang continue to carry forward.

\section{Acknowledgments}

This paper was the general project of humanities and social science in Sichuan Education Department in 2014, and the topic name is Research on Martial Arts of Qiang Group. The project number was 14 SB0293.

\section{References}

[1] Qin Rongzhou.The exploration of Qiang martial art. Bulletin of Sport Science and Technology,2014,(11):3-4.

[2] Wang Hongshen,Huo Hong.Study on traditional sports of Qiang Group. Sport Culture Guide,2010,(8):128-131.

[3] Feng Yao.Study on the “Loricae Dance”of Qiang Group. Minzu University of China,2007.40-43. 